\title{
RESISTANCE OF SWEET PEPPER GENOTYPES TO ABIOTIC STRESSES IN GROWING CONDITIONS OF LOW-CAPACITY HYDROPONICS
}

\section{O.N. PYSHNAYA, M.I. MAMEDOV, E.G. BELAVKIN, E.G. KOZAR', E.A. DZHOS, A.A. MATYUKINA}

\author{
All-Russian Research Institute for Vegetable Breeding and Seed Production, Federal Agency of Scientific Organiza- \\ tions, 14, ul. Selektsionnaya, pos. VNIISSOK, Odintsovo Region, Moscow Province, 143080 Russia, e-mail vniis- \\ sok@mail.ru, pishnaya_o@mail.ru \\ Acknowledgements: \\ Supported by grant of Ministry of Education and Science of the Russian Federation (State Contract № 16.M04.11.0004 of \\ April 19, 2011)
}

Received July 14, 2015

\section{Abstract}

The modern trend of vegetable crop breeding is a development of new cultivars and hybrids resistant to abiotic and biotic stresses and suitable for fully mechanized agriculture. It can provide the maximal commercial output and high profitability of vegetable growing. Pre-breeding is based on knowledge of impact of various abiotic factors on the yield and productivity of certain genotype in specific growing conditions. Traditionally the pepper plants are cultivated in greenhouses on low-volume soil or artificial medium with drop irrigation. Main advantage of low-volume technologies is a labor saving and improved phytosanitary conditions. In the present paper, the response of different sweet pepper (Capsicum annuum L.) genotypes to various abiotic factors has been studied aiming at development of initial breeding material for new varieties and hybrids under the hydroponic system conditions. The investigation has been conducted in 2008-2014 in the All-Russian Research Institute for vegetable breeding and seed production (Moscow Province). The breeding and collection samples of sweet pepper as well as $F_{1}$ hybrid Raisa (standard) were used in the present study. Plants were grown in a greenhouse on sphagnum peat mixed with calcified substance as a potting substrate and mineral fertilizers. The concentration of nutrient solution for irrigation of seedlings conforms to the recommended standard. The growth conditions were partially controlled. The parameters of outside environment were recorded during growing period using an automated climate control system KISTOCK KH-100 (France). The soil temperature was also controlled. Yield sample characteristics and assessment were done by UPOV system (Union Internationale pour la protection des obtentions végétales, France). The most adverse factores were recorded in the beginning (February-May) and the end (SeptemberOctober) of growing season regardless of year of investigation, that resulted in decreasing marketability of the yield. The unmarketable part of yield was represented by fruits with excessive growth, deformation, and affected by blossom-end rot. Long-term screening of pepper genotypes on responsiveness to unfavorable factors of environment allowed to divide the cultivars into the following groups: susceptible (cv. Agapovskii), low-susceptible (cv. Elisa), and tolerant (cv. Zheltiyi buket). At hydroponics, productivity of the susceptible cultivar Agapovskiy was decreased up to $40 \%$ as compared with the tolerant cultivar Zheltiyi buket. It was shown that adaptability of sweet pepper varieties to the conditions of lowcapacity hydroponics is defined by the norm of reaction to changes of environmental factors such as daily temperature, difference of night and day temperatures, humidity, and its combinations. Changes of the light intensity are not so crucial for cultivars productivity; it may have negative impact on varieties with low adaptability when combined with other environment parameters. The correlation between the rate of non-standard part of yield, the damage of fruits caused by blossom-end rot, and the microclimate parameters differed among the varieties. Development of non-standard fruits in the susceptible and the low-susceptible cultivars is due to low humidity (at $r$ value ranged from -0.65 to -0.72 ), while in the tolerant cultivars it depends on a big difference between the day and night temperatures (at $r>+0.70$ ). Damage of fruits caused by blossom-end rot is more genotype dependent. In all genotype, it is promoted by huge temperature changes, being stronger related to this factor in the susceptible genotypes at $r=0.65-0.75$. For development of new pepper varieties and hybrids suitable for low-capacity hydroponics, the initial breeding material with high norm of reaction to temperature and high resistance to low humidity must be selected.

Keywords: sweet pepper (Capsicum annuum L.), adaptivity, temperature, humidity, environmental factors, yield, productivity, blossom end rot, norm of reaction, breeding. 
Sweet pepper (Capsicum annuum L.) is cultivated in greenhouses using soil and soil-containing or artificial substrates with drip irrigation. The small scale technology of growing vegetables improves the fertilizer utilization coefficient, increases the yield and prevents environmental pollution. The main advantages of this technology are savings of labour and substrates costs, improved phytosanitary conditions, and enhanced production standards [1, 2]. However, the cultivation of pepper varieties, intended for other technologies, under conditions of low-capacity hydroponics often leads to an increase in a non-marketable part of the yield, especially under adverse conditions of early spring and autumn to winter periods [3].

Sweet pepper culture is responsive to even minor changes in environmental factors $[4,5]$. Thus, with a dramatic decrease in night temperatures, fruit formation does not occur quickly enough, pistil and anthers grow along with the fruit resulting in excessive growth or irregularly shaped fruits. When the temperature difference increases by more than $10{ }^{\circ} \mathrm{C}$, decreases in the yield may be as high as $1 \mathrm{~kg} / \mathrm{m}^{2}[6,7]$. Too high temperature $\left(35^{\circ} \mathrm{C}\right.$ or above) results in an overall depression of the plants, causes elongation of the pistil column, abscission of flowers and ovaries, especially at the lack of air and soil humidity [8-10]. The optimum of soil temperatures for sweet pepper ranges within $20-25{ }^{\circ} \mathrm{C}$. Its reduction to $18{ }^{\circ} \mathrm{C}$ stimulates abundant flowering, but the fruits appear to be deformed, flattened, and non-marketable. Lower temperatures $\left(15^{\circ} \mathrm{C}\right)$ will cause vegetative growth retardation and transition to the reproductive phase of development, reinforce the abscission of flowers and young fruit, and increase the risk of root rots [11, 12].

Low lighting conditions significantly extends all the stages of pepper organogenesis, delaying the transition to the reproductive stage, and causes abscission of buds and ovaries. Abscission of flowers and fruits is associated with a reduction in the photosynthesis activity and reduced formation of photoassimilates, as well as with alterations in their distribution within the plant $[5,11,13]$.

Solanaceae plants are also demanding to substrate and air humidity. At the stage of the reproductive organ formation, the substrate moisture should be maintained within the range of 60-70\% PPV before fruiting and $80 \%$ during the period of fruiting. Insufficient air humidity slows the growth of leaf mass, causes abscission of flowers and young ovaries. Relative humidity of at least $70-80 \%$ is considered suitable for sweet pepper plants. Very high humidity or soggy soil reduce the growth [14-16].

Drip irrigation in the small scale technology of plant growing involves the use of high salt concentrations, with subsequent gradual salinization of the substrate, increased osmotic pressure, and an effect of «physiological drought», which causes blossom-end rot (BER) on fruits, especially at high temperature and high fruit burden on the plant [16-19]. This physiological disease is associated with changes in metabolism as a result of violations in moisture regime and transpiration, when the plant being in the ripening phase is suffering from a lack of moisture, especially when combined with periods of enhanced transpiration, or when water loss through the leaves is more higher than its absorption by roots. Calcium deficiency also increases the manifestation of BER symptoms, although the lack of this element in the soil does not always become the direct cause of the BER [20-22].

The cultivars and hybrids being created should include the desired combination of commercially important traits with high resistance to biotic and abiotic stresses. The plant resistance is a genetically regulated trait, which is characterized by the reaction norm of genotype to the exposure to adverse factors. Under optimal conditions, it is latent, being realized only when the plant is 
exposed to an extreme factor.

Years of our research have resulted in the first ever identification of the combination of the most significant factors affecting the obtainment of marketable sweet pepper yield when using a small scale technology. Furthermore, we obtained lines with a high reaction norm that can be used to develop advanced, highly adapted sweet pepper forms.

The aim of our work was to study the response of different genotypes of sweet pepper plants to a variation of main abiotic factors and creation of source material to produce competitive cultivars and hybrids to be used under the small scale hidroponics.

Technique. The investigation has been conducted in 2008-2014 in AllRussian Research Institute for Vegetable Breeding and Seed Production (VNIISSOK) using a modern greenhouse complex by Richel Group (France). Cultivars, breeding and collection samples of sweet pepper from the gene pool of the VNIISSOK were used, and the reference was the $\mathrm{F}_{1}$ hybrid Raisa originated by the breeding company Enza Zaden (The Netherlands). Sweet pepper plants under trial were grown on the «Professional» (Russia) substrate, which included sphagnum peat mixed with lime substances and mineral fertilizers. Samples were planted by $20-30$ plants without repetitions, and a reference was placed between every 10 samples.

The concentration of the nutrient solution for irrigation of cassettes with seedlings, seedling pots and mats conformed to the recommended standards for solanaceous crops [23-25]. Supply of the nutrient solution into the mats was carried out through droppers. One day before the planting, the substrate was moistened with a nutrient solution with electrical conductivity (EC) 2.3-2.5 mS. During the season, EC of the solution under high lighting conditions was 3.5-4.0 mS, on cloudy days it was increased to $4.0-4.5 \mathrm{mS}$. Plants were grown with tying on a trellis to form two stems.

For seedlings (January to February), optimal temperature and light conditions were maintained considering the phase of plant development [12, 24, 25]. For young and adult plants the growing conditions were partially controlled (due to the absence of autonomous heating, air-conditioning and additional lighting) with the main parameters recorded continuously during the entire growing period by an automated climate control system KISTOCK KH-100 (France) and the substrate temperature measured by laboratory thermometers.

Fruit yield sample characteristics were assessed by the UPOV system (Union Internationale pour la protection des obtentions végétales, France) based on the complete yield structure analysis, i.e. marketable (standard) and nonmarketable (non-standard and sick fruits) parts. In addition, phenological phases of development of the plant reproductive organs were recorded over time, with simultaneous recording of the main environmental parameters.

Mathematical and statistical processing of the results was carried out based on appropriate methods [26] using the Microsoft Excel 2003 application package.

Results. Many years of observations have revealed changes in the main parameters when growing sweet pepper plants according to the small scale technology with no strict control of the microclimate in the greenhouses.

Mean annual values of day and night temperature during the entire growing period did not usually go beyond a favourable range for the crop. The day air temperature was $21-28^{\circ} \mathrm{C}$, and night air temperature was $16-18{ }^{\circ} \mathrm{C}$, with the exception of two months (February and September), when night temperature averaged to $1-3{ }^{\circ} \mathrm{C}$ below the optimum (Fig. 1, A).

However, average daytime air temperatures within each month of the grow- 
ing period (see Fig. 1, B) often did not meet the optimum values $\left(+21 \ldots+23{ }^{\circ} \mathrm{C}\right)$. This can be explained by significant fluctuations in temperature and, accordingly, by a wide variation of differences between daytime and night-time temperature, from 1 to $17{ }^{\circ} \mathrm{C}$ (see Fig. 1, A, B).
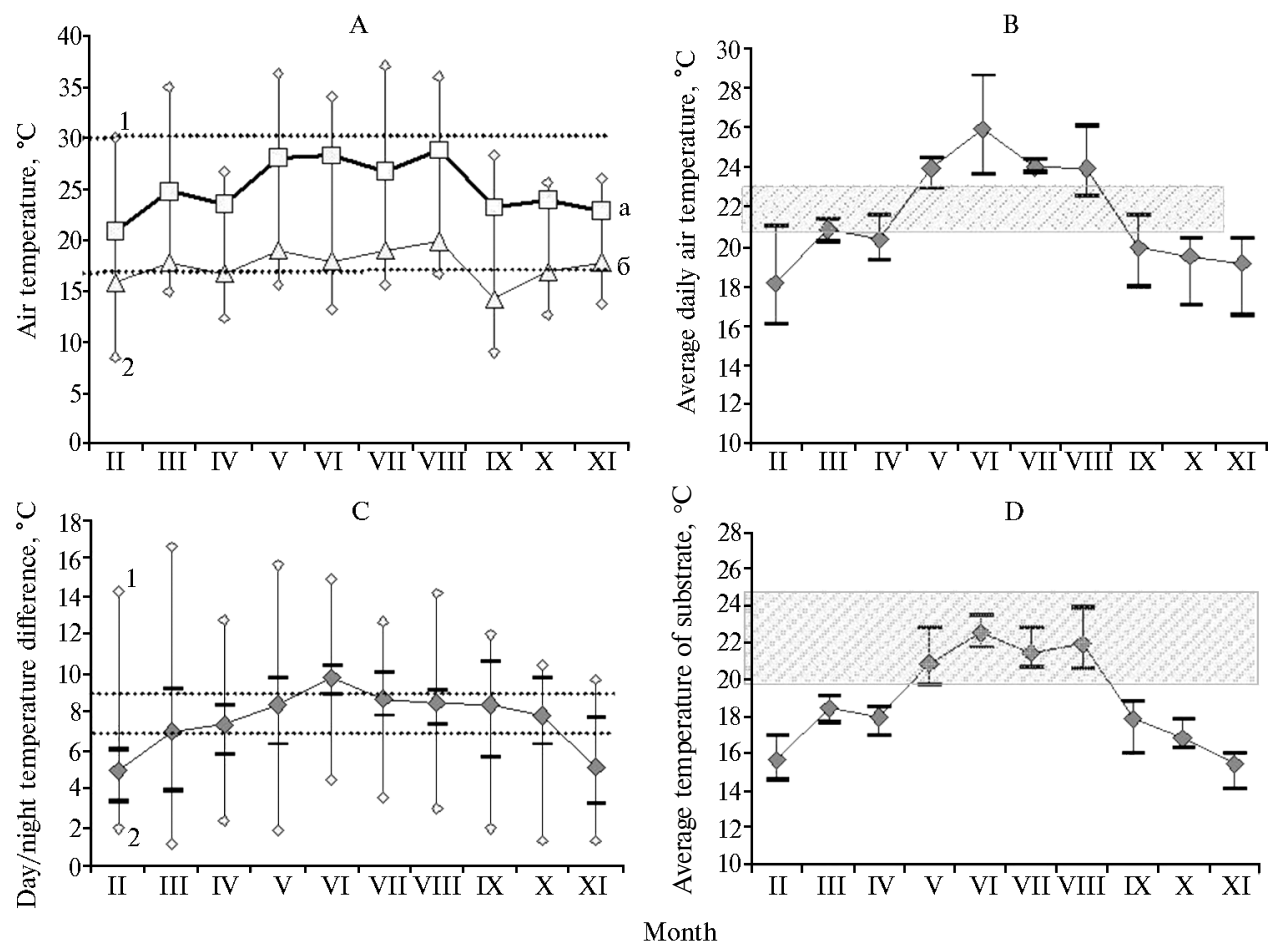

Fig. 1. Air and substrate temperature recorded monthly during the growth of sweet pepper (Capsicum annuum L.) plants in greenhouse under small scale technology: A - day (a) and night (б) air temperature, $\mathrm{B}$ - average daily air temperature, $\mathrm{C}$ - temperature difference (day/night), D - average temperature of substrate; II-XI - February to November, respectively (Moscow region, 20082012). The diagrams show average annual values and a range of mean deviations by year; the diagrams A and C represent the upper (1) and lower (2) limits of daily fluctuations. Dotted lines and shaded areas designate areas of optimal settings for the culture of sweet pepper [24, 25].

According to annually recorded data, a more favourable average daily temperature appeared to be in March and April, while in February and autumn months it was most often below the optimum, and in the summer months it was above the optimum (on average of $1-5{ }^{\circ} \mathrm{C}$ ). The average temperature of the substrate in summer months was favourable for the development of sweet pepper plants, i.e. $+20 \ldots+24{ }^{\circ} \mathrm{C}$, while in spring and autumn it dropped markedly below the optimum (see Fig. 1, D). Lowering the temperature in the root zone $\left(<16^{\circ} \mathrm{C}\right)$, especially in spring, restrained the vegetative growth and increased the abscission of flowers and ovaries. However, too high substrate temperature $\left(>25^{\circ} \mathrm{C}\right)$, which have been registered, for example, in August 2007 and June 2008, also resulted in poor fruit set and emergence of BER.

Another distinctive feature of small scale technology of cultivation was reduced humidity in the greenhouse (Fig. 2, A). Its average annual values were significantly lower than the optimal values for almost entire vegetative period $(<60 \%)$, and only in certain years they were within the required limits (62-70\%), mainly in the summer months, with the maximum fluctuations in August (38 to $76 \%$ ).

Illuminance was changed in accordance with the characteristics of the Moscow region (see Fig. 2, B). The highest light intensity was recorded in June 
and July, with a significant variation of the average values seen in some years $(24,000$ to $45,000 \mathrm{~lx})$.
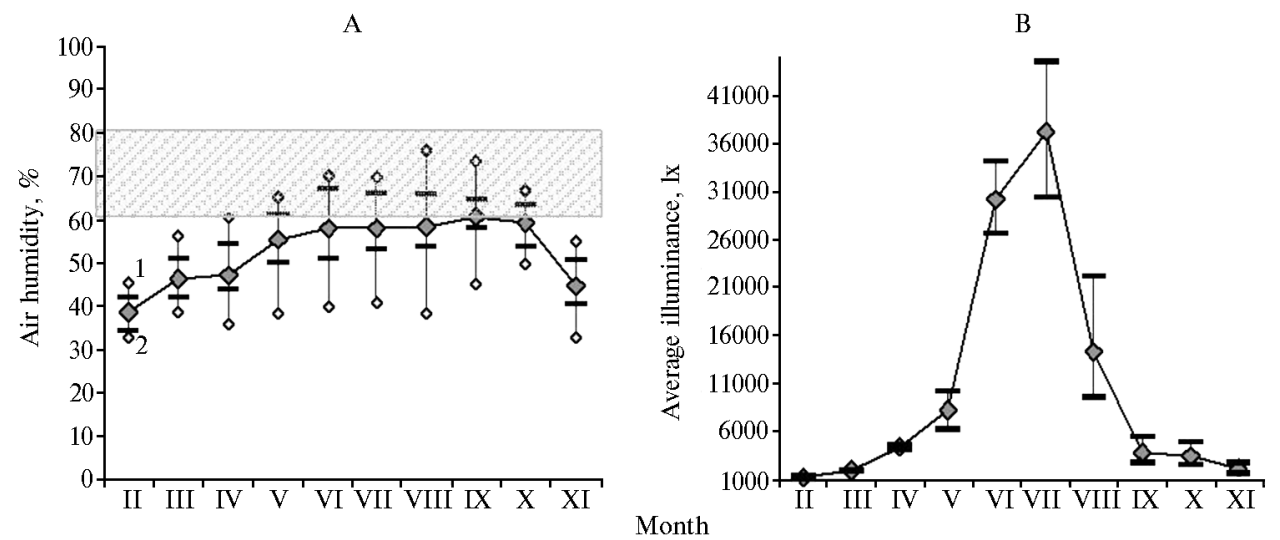

Fig. 2. Air humidity (A) and illuminance (B) recorded monthly during the growth of sweet pepper (Capsicum annuum L.) plants in greenhouse under small scale technology: II-XI - February to November, respectively (Moscow region, 2008-2012). The diagrams show the average annual values and a range of mean deviations by year; the diagram A represents the upper (1) and lower (2) limits of daily fluctuations. The shaded zone designates an area of optimal settings for the crop [24, 25].

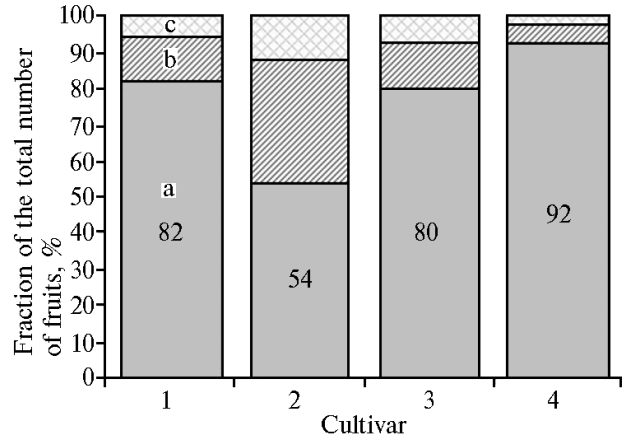

Fig. 3. The yield structure in sweet pepper (Capsicum annuum L.) cultivars from different groups of susceptibility to growing in greenhouse under small scale technology: $1-\mathrm{F}_{1}$ Raisa (reference); 2 - Agapovskii (susceptible); 3 Elisa (low susceptible); 4 - Zheltiyi buket (resistant); a - a marketable yield part; b - a non-standard part; c - fruits with blossom-end rot (Moscow region, 2008-2012). to unfavourable environmental factors [7], i.e. susceptible, low susceptible and tolerant (resistant), the most typical representatives of which were the Agapovskii, Elisa and Zheltiyi Buket cultivars, respectively (Fig. 3). Marketability (productivity) of the susceptible cultivar Agapovskii was decreased on average up to $40 \%$ as compared to the tolerant cultivar Zheltiyi Buket. These specimens have clearly showed that they have different requirements to environmental conditions, especially to temperature and humidity profile (Fig. 4).

A non-standard portion of the yield in the Agapovskii cultivar, consisted mainly of fruits with extensive growth, was largely determined by low air humidity, especially at lowered average overnight temperatures and low illuminance. A non-standard fruits in the Elisa cultivar also emerged mainly at the lowered air humidity and lightening (see Fig. 4). The emergence of such fruits in the cultivar Zheltiyi Buket and the hybrid $\mathrm{F}_{1}$ Raisa was mainly determined by the tempera- 
ture profile, especially the difference between day and night temperature. At the same time, the effect of the average air temperature was more pronounced in the cultivar Zheltiyi Buket (see Fig. 4).
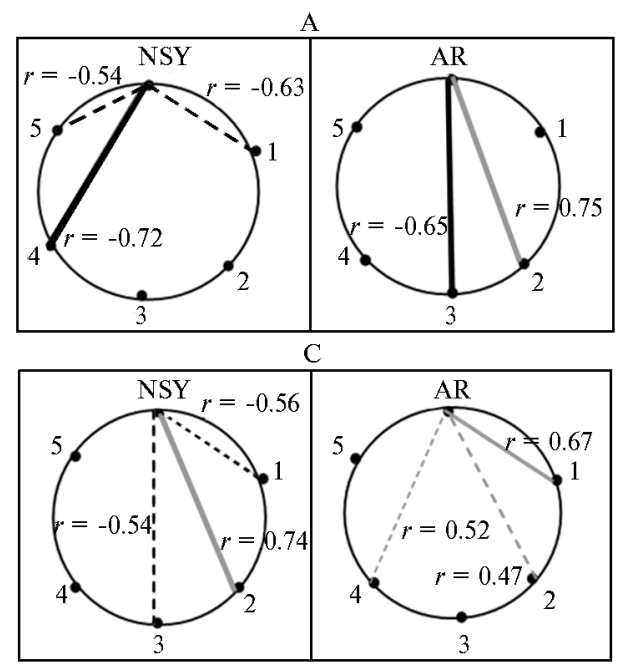

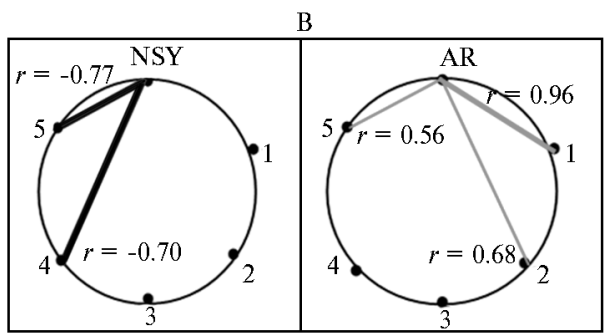

$\mathrm{D}$

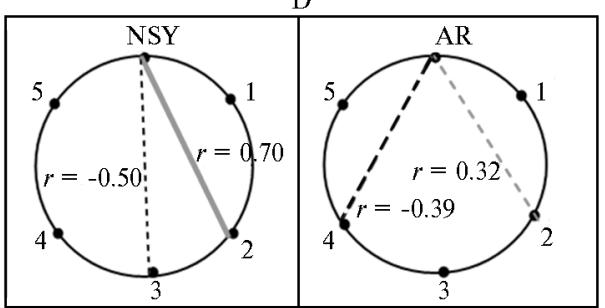

Fig. 4. Correlations between environmental factors and the portion of non-standard fruits (NSY) and those affected by the blossom-end rot (BER) in the sweet pepper (Capsicum annuum L.) cultivars Agapovskii (susceptible, A), Elisa (low susceptible, B), Zheltiyi Buket (resistant, C), and $\mathrm{F}_{1}$ Raisa (reference, D), when grown in greenhouse under small scale technology: 1 - average daily temperature, ${ }^{\circ} \mathrm{C} ; 2-$ day/night air temperature difference, ${ }^{\circ} \mathrm{C} ; 3$ - the substrate temperature, ${ }^{\circ} \mathrm{C} ; 4$ - relative air humidity, \%; 5 - illuminance, $\mathrm{lx}$ (average values per month of vegetation) (Moscow region, 2008-2012). Positive correlation is showed in grey, negative correlation in black; the degree of contingency is represented by line thickness.

Other patterns were observed in the blossom-end rot. In all specimens, the appearance of BER was provoked by dramatic changes in temperature, and the impact of this factor was more pronounced in the susceptible samples. Air humidity exerted a lower effect on the BER development, and this relationship was cultivar-specific. In addition, increased BER in fruits was caused by a low temperature of the substrate in the Agapovskii cultivar, or by an increase in average air temperature in the Zheltiyi Buket cultivar, or by an increased air temperature at high illuminance in the Elisa cultivar (see Fig. 4).

A small part of close correlation between the emergence of the nonmarketable yield part and the environmental parameters appeared to be attributable to the complex character of the response of sweet pepper cultivars to changes in the factors investigated.

It has been established that the response of the samples to changes in exogenous factors can be assessed by comparing the marketability by the specific harvesting date and the average values of the studied environmental parameters during the interphase period of blooming to fruit biological ripeness. This period averaged to 60 days, but it must be specified individually for each sample. Plotting the influence curves of the non-standard or BER damaged fruit output against the investigated external parameters revealed the causal factors for the decline of marketability, and allowed to determine the reaction norm of the genotype to each of them. This is clearly exemplified by changes in the yield structure (the proportion of marketable, non-standard and BER damaged fruits) depending on humidity and average air temperatures. The revealed relationships were nonlinear and polynomial cubic and quartic in the curve shape (Fig. 5).

The obtained results indicate significant differences in the reaction norm of sweet pepper cultivars from different groups of responsiveness to the main en- 
vironmental parameters. We managed to determine the optimal range, providing high marketability of the fruit under low-capacity hydroponics.

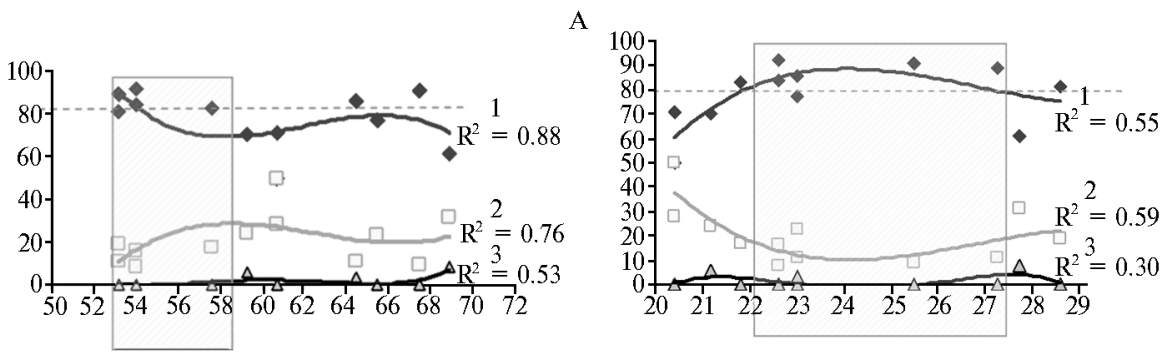

B
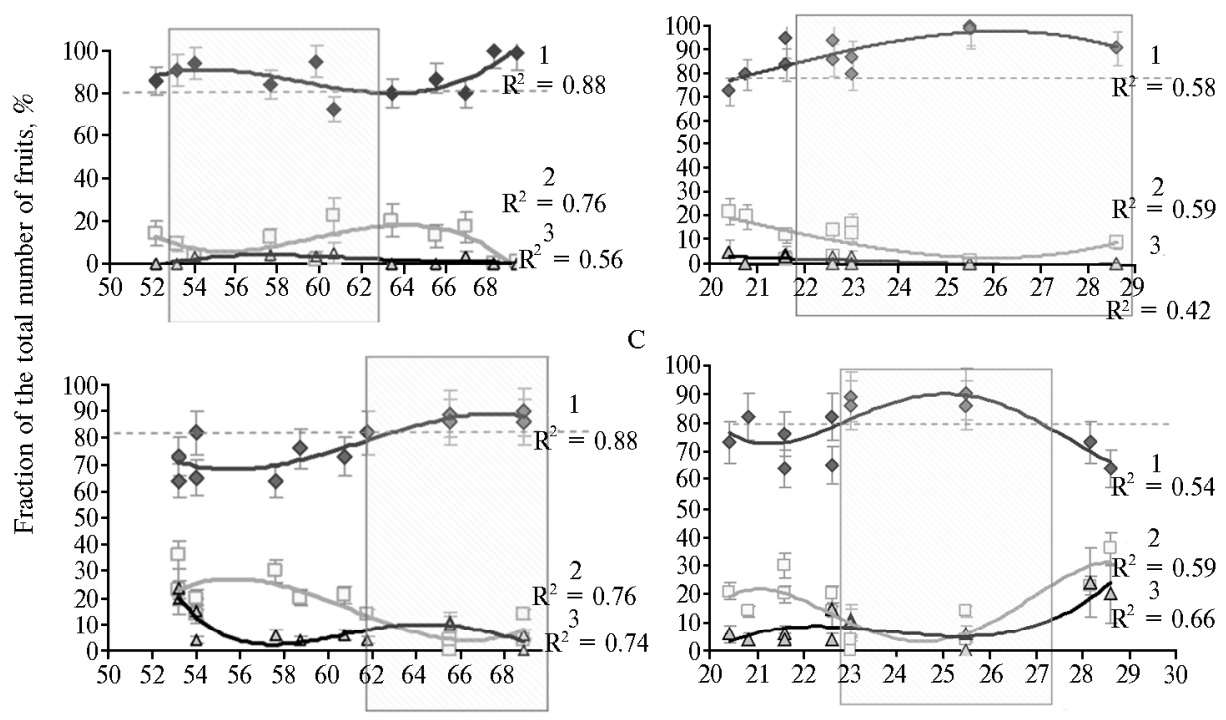

$\mathrm{C}$
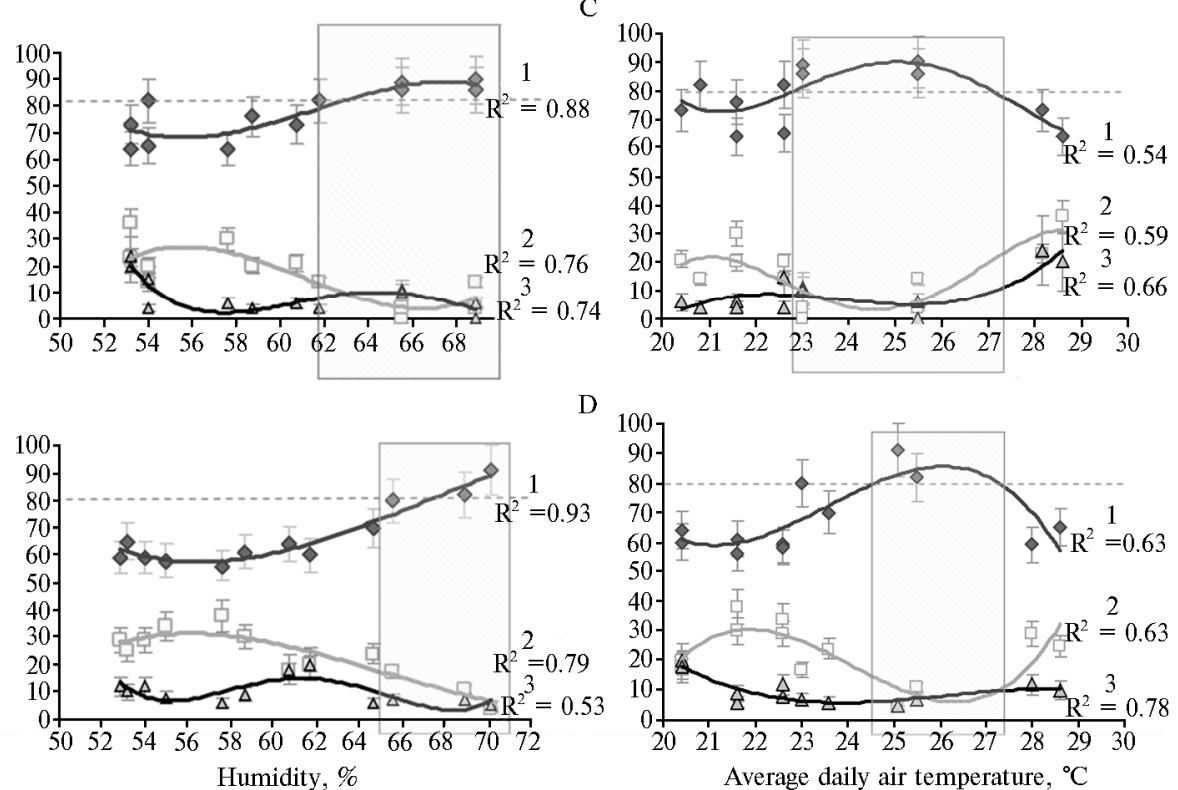

Fig. 5. The yield structure in the sweet pepper (Capsicum annuum L.) cultivars $\mathrm{F}_{1}$ Raisa (reference, A), Zheltiyi Buket (tolerant, B), Elisa (low susceptible, C), Agapovskii (susceptible, D) depending on the humidity (left) and average daily air temperature (right) in the greenhouse when growing under small scale technology: 1 - fruit marketability; 2 - a non-standard yield portion; 3 - the yield affected by blossom-end rot (Moscow region, 2008-2014). Hatching covers the range of optimal values of the exogenous parameters for the cultivars.

For the $\mathrm{F}_{1}$ hybrid Raisa (reference) grown under cover in the Nonchernozem zone, the optimal conditions were air temperature up to $22.5-27.5{ }^{\circ} \mathrm{C}$ and 54-58\% humidity. A decrease or increase in temperature led to an increase in the non-standard portion of the yield or, when combined with high humidity, to the appearance of the fruits affected by blossom-end rot. Another key factor was the difference between day and night temperatures, optimal values of which ranged from 5.7 to $9.5^{\circ} \mathrm{C}$. A significant temperature difference (over $10{ }^{\circ} \mathrm{C}$ ) influenced the fruit yield most adversely.

In general, based on the evaluation of responsiveness to exogenous fac- 
tors, the chosen reference cultivar appeared to be between susceptible and low susceptible groups of specimens. Thus, the Zheltiyi Buket cultivar (susceptible group) was reported to have a higher reaction norm to the changes for the most of the studied parameters. The humidity optimum was within $52 \%$ to $70 \%$, and the temperature optimum averaged from $21^{\circ} \mathrm{C}$ to $29^{\circ} \mathrm{C}$ with a day/night difference of $5{ }^{\circ} \mathrm{C}$ to $10.5{ }^{\circ} \mathrm{C}$. This explains the high yield and marketability of the Zheltiyi Buket cultivar fruits throughout the entire vegetation season.

Representative specimens of low and high susceptible groups (Agapovskii and Elisa cultivars) required a more strict optimal range to ensure the highest marketability, such as air humidity at least $62 \%$ for the Agapovskii cultivar and $65 \%$ for the Elisa cultivar; the optimum of average daily temperatures was 24.5$27.5^{\circ} \mathrm{C}$ and $23-27{ }^{\circ} \mathrm{C}$, respectively with day/night difference lying within $9{ }^{\circ} \mathrm{C}$ to $10.5^{\circ} \mathrm{C}$. Low adaptiveness of these cultivars to the small scale technology seems to be related to their selection for growing in plastic film greenhouses, which are characterized by a higher humidity and drastic temperature fluctuations.

Many years of our research have resulted in the development of the sweet pepper $F_{1}$ heterotic hybrid Mila with a high reaction norm, which appeared to be capable of fruiting at different edaphic factors. The hybrid is characterized by high crop yield of $25 \mathrm{~kg} / \mathrm{m}^{2}$ on average, marketability over $95 \%$, and fruit quality.

Therefore, the average daily temperature, the difference between day and night temperatures, relative air humidity and their combination are essential for ensuring the standard sweet pepper production output when plant growing in greenhouse under the small scale technology. Illuminance has a less significant impact on the product merchantability, and may act as an additional adverse factor, together with other environmental parameters, affecting cultivars with low adaptive capacity. Therefore, when developing sweet pepper cultivars and hybrids to be used under the small scale technology, the breeding material with a high norm of reaction to the temperature and high resistance to low humidity must be initially selected. An important criterion for the adaptiveness of individual genotypes and selection samples on the pre-breeding stage is the index of marketability. Based on long term evaluation and breeding (2008-2014), we have produced sweet pepper lines with a high reaction norm, which was involved in hybridization to create promising heterotic hybrids and new highly adapted forms with a combination of features essential for growing under conditions of low-capacity hydroponics.

\section{R E F E R E N C ES}

1. Tognoni F., Serra G. Trends in process technologies and products. Acta Horticulturae, 2003, 614: 65-75 (doi: 10.17660/ActaHortic.2003.614.7).

2. Korol' V.G. Gavrish, 2009, 1: 44-45.

3. Krivosheeva N.P., Engaly cheva I.A., Mitrofanova O.A. Kartofel' i ovoshchi, 2007, 2: 26.

4. $\mathrm{O}$ u L.J., $\mathrm{Z}$ o u X.X. The photosynthetic stress responses of five pepper species are consistent with their genetic variability. Photosynthetica, 2012, 50(1): 49-55 (doi: 10.1007/s11099-0120008-8).

5. Cho Y.Y., Le e Y.-B., O h M.-M., S o n J.E. Application of quadratic models for establishment of adequate temperature ranges in germination of various hot pepper (Capsicum annuum L.) cultivars. Research Report Protected Horticulture. Horticulture, Environment, and Biotechnology, 2012, 53(3): 222-227 (doi: 10.1007/s13580-012-0039-x).

6. B a k k r J.C. The effects of temperature on flowering, fruit set and fruit development of glasshouse sweet pepper (Capsicum annuum L). J. Horticultural Science, 1989, 64: 313-320.

7. $\mathrm{Press}$ m a E., Shaked R., Firon N. Exposing pepper plants to high day temperatures prevents the adverse low night temperature symptoms. Physiologia Plantarum, 2006, 126: 618626 (doi: 10.1111/j.1399-3054.2006.00623.x).

8. D e Swa rt E.A.M. Potential for breeding sweet pepper adapted to cooler growing condi- 
tions - a physiological and genetic analysis of growth traits in Capsicum. Wageningen, 2007.

9. De Swart E.A.M., Marcelis L.F.M., Voorrips, R.E. Variation in relative growth rate and growth traits in wild and cultivated Capsicum accessions grown under different temperatures. Journal of Horticultural Science \& Biotechnology, 2006, 81: 1029-1037.

10. Kafizadeh N., C a rapetian J., K a lantari K.M. Effects of heat stress on pollen viability and pollen tube growth in pepper. Research Journal of Biological Sciences, 2008, 3(10): 1159-1162.

11. Tiwari A. Parthenocarpic fruit development in Capsicum annuum. Thesis. Wageningen University, Wageningen, the Netherlands, 2011.

12. B elogubova E.N., Vasil'ev A.M., Gil' L.S., Pashkovski i A.I. Sovremennoe ovoshchevodstvo zakrytogo i otkrytogo grunta [Current techniques for olericulture in a field conditions and greenhouses]. Moscow, 2007.

13. Ul'k o O.O. Sovershenstvovanie elementov tekhnologii vyrashchivaniya pertsa sladkogo v zimnikh teplitsakh v usloviyakh 3-i svetovoi zony. Avtoreferat kandidatskoi dissertatsii [An improved technology for growing pepper plants in greenhouses under light conditions of mid latitudes. PhD Thesis]. Moscow, 2005.

14. Aloni B., Dai e J., Karni L. Water relations, photosynthesis and assimilate partitioning in leaves of pepper (Capsicum annuum) transplants: effect of water-stress after transplanting. $J$. Horticultural Science, 1991, 66: 75-80.

15. Yao C., Moreshet S., Aloni D., Karni L. Effects of water stress and climatic factors on the diurnal fluctuations in diameter of bell pepper fruit. Journal Horticultural Science and Biotechnology, 2000, 75: 6-11.

16. S t a ry k h G.A., K a y u m o v M.K. Gavrish, 2005, 5: 18.

17. I g n a t o va S.I., S k o rubs k a y a.I. Kartofel' $i$ ovoshchi, 2009, 10: 26-27.

18. G ris he c h ki n a L.D. Zashchita i karantin rastenii, 2011, 2: 16-18.

19. N avarro J.M., Garrido C., M a rtínez V., C a rvajal M. Water relations and xylem transport of nutrients in pepper plants grown under two different salts stress regimes. Plant Growth Regulation, 2003, 41(3): 237-245 (doi: 10.1023/B:GROW.0000007515.72795.c5).

20. K holode ts ki i M.S. Mir teplits, 2009, 3: 23.

21. Ro ne n I a 1. Gavrish, 2006, 6: 29-33.

22. Tadesse T., Nichols M.A., Hewett E.W., F is he r K.J. Relative humidity around the fruit influences the mineral composition and incidence of blossom-end rot in sweet pepper fruit. Journal Horticultural Science and Biotechnology, 2001, 76(1): 9-16.

23. R o n e n I a l. Gavrish, 2006, 3: 14-17.

24. Albright L.D. Controlling greenhouse environments. Acta Horticulturae, 2002, 578: 47-54 (doi: 10.17660/ActaHortic.2002.578.4).

25. Teplichnyi praktikum. Pertsy i baklazhany (daidzhest zhurnala «Mir teplits») /Sostavitel' A.D. Tsydendambaev [Greenhouse workshop: pepper plant and eggplant cultivation (a digest of Greenhouse World Magazine. A.D. Tsydendambaev (compiler)]. Moscow, 2012.

26. D o s p e k h o v B.A. Metodika polevogo opyta [Methods of field trials]. Moscow, 1985. 